\title{
Safety of Oral Clemastine - Analysis of Data from Spontaneous Reporting System in Poland
}

\author{
Stanisław Han ${ }^{1}$, Katarzyna Karłowicz-Bodalska ${ }^{1}$, Katarzyna Miśkiewicz², \\ Elżbieta Kutycka ${ }^{3}$ and Ernest Kuchar ${ }^{2 *}$ \\ ${ }^{1}$ Department of Industrial Pharmacy, ${ }^{2}$ Department of Pediatric Infectious Diseases, Wroclaw Medical University, Poland, \\ ${ }^{3}$ Pharmacovigilance Department, PPF HASCO-LEK S.A. Wroclaw, Poland
}

*For correspondence: Email: ernest.kuchar@gmail.com; Tel: +48717703156

\begin{abstract}
Purpose: To analyse the safety of oral clemastine marketed in Poland based on spontaneous adverse event reporting system.

Methods: We analyzed sales volume and data obtained from the monitoring of spontaneous reports on the adverse effects of Clemastinum Hasco tablets $(1.0 \mathrm{mg})$ and Clemastinum Hasco syrup $(0.1 \mathrm{mg} / \mathrm{mL})$ received by the manufacturer (PPF HASCO-LEK S.A. Wroclaw, Poland) and National Monitoring Centre in Warsaw in the period January 2007 to June 2012. The Polish system is mainly based on written reports voluntarily submitted by healthcare professionals.

Results: A total of 2,089,717 units of Clemastinum Hasco tablets $1.0 \mathrm{mg}$ and 1,965,340 units of Clemastinum Hasco syrup $0.1 \mathrm{mg} / \mathrm{mL}$ were marketed during the period analyzed. Only one spontaneous report on clemastine was registered in the period analyzed.

Conclusion: Oral clemastine is a safe medication, rarely causing adverse effects; Nevertheless, the existing spontaneous monitoring system for adverse effects in Poland may not be sensitive enough and therefore, needs improvement.
\end{abstract}

Keywords: Clemastine, Adverse drug reactions, Pharmoepidemiology, Drug safety, Pharmacovigilance, Reporting system

Tropical Journal of Pharmaceutical Research is indexed by Science Citation Index (SciSearch), Scopus, International Pharmaceutical Abstract, Chemical Abstracts, Embase, Index Copernicus, EBSCO, African Index Medicus, JournalSeek, Journal Citation Reports/Science Edition, Directory of Open Access Journals (DOAJ), African Journal Online, Bioline International, Open-J-Gate and Pharmacy Abstracts

\section{INTRODUCTION}

An ethanolamine-derivative, clemastine, is a widely used first-generation antihistamine. Patented in 1963, clemastine was introduced to pharmaceutical markets in France, Switzerland and West Germany in 1967 by Sandoz under the name Tavegil $\circledast$ and is now sold in 22 countries [1]. Clemastine acts as a competitive antagonist on $\mathrm{H} 1$ histamine receptors. The drug inhibits both the vasodilator and vasoconstrictor effects of histamine, respiratory and gastrointestinal smooth muscle constriction, which makes it useful in the treatment of skin allergies (contact dermatitis, itching, urticaria) and allergic rhinitis (it helps relieve rhinorrhea, sneezing and lacrimation).

The most significant and frequent adverse effects of clemastine reported in the literature are CNS depression or paradoxical stimulation, manifested as drowsiness, psychomotor impairment, concentration problems, dizziness and headache, fatigue, sedation, disturbed coordination, and cholinolytic effects resulting in dry mouth and the thickening of bronchial secretions [2]. Other adverse effects include 
insomnia, vertigo, tachycardia, nausea, vomiting, diarrhea or constipation, blurred vision, photophobia, and urination difficulties in men suffering from benign prostatic hyperplasia, which is a predisposing factor. Therapeutic doses of clemastine may interfere with color vision [3]. Allergic rash and erythema have also been reported. Table 1 below lists the adverse effects contained in the summary of product characteristics for the reference drug, Tavegil $囚$.

PPF HASCO-LEK S.A. manufactures medicinal products with clemastine in the form of tablets containing $1 \mathrm{mg}$ of the drug and $1 \mathrm{mg} / 10 \mathrm{~mL}$ syrup: Clemastinum Hasco tablets and Clemastinum Hasco syrup. Clemastinum Hasco medicinal products have been available on the Polish pharmaceutical market since the beginning of 2007. The manufacturer, as the Marketing Authorisation Holder (MAH), has a pharmacovigilance system at their disposal, which is based on current EU legislation. As part of the pharmacovigilance system, the MAH monitors spontaneous reporting i.e. adverse reaction reports submitted by healthcare professionals and patients or their carers and world literature. PPF HASCO-LEK SA cooperates closely with the Office for
Registration of Medicinal Products, Medical Devices and Biocidal Products based in Warsaw, which is the central pharmacovigilance unit in Poland. The monitoring actions aim to detect new drug interactions and adverse reactions as well as groups of patients with a more frequent occurrence of adverse reactions.

\section{EXPERIMENTAL}

Analysis of the safety of clemastine in the form of tablets and syrup manufactured by HASCO-LEK

Data concerning clemastine sales volumes and adverse reaction reports from Poland available in a passive spontaneous reporting system were analyzed, covering the period between January 2007 and June 2012. A systematic review of the literature was also conducted and, for that purpose, electronic databases were searched using the following keywords, with the search being limited to the time period specified above:

(a) Toxnet (http://toxnet.nlm.nih.gov/Clemastine): "Clemastine" OR Clemastine Fumarate" OR "klemastyna” OR “15686-51-8” OR “14976-57-9”

Table 1: Clemastine's adverse effects as listed in Tavegilß Summary of Product Characteristics (reference drug)

\begin{tabular}{ll}
\hline Adverse effect & Incidence \\
\hline Nervous system disorders: & common $(>1 / 100,<1 / 10)$ \\
Fatigue & common $(>1 / 100,<1 / 10)$ \\
Drowsiness & uncommon $(>1 / 1,000,<1 / 100)$ \\
Dizziness & rare $(>1 / 10,000,<1 / 1,000)$ \\
Headache & \\
Psychiatric disorders: & rare $(>1 / 10,000,<1 / 1,000)$ \\
Excitability & rare $(>1 / 10,000,<1 / 1,000):$ \\
Gastrointestinal disorders: & rare $(>1 / 10,000,<1 / 1,000)$ \\
Gastrointestinal disorders & very rare $(<1 / 10,000)$ \\
Nausea & rare $(>1 / 10,000,<1 / 1,000)$ \\
Constipation & very rare $(<1 / 10,000)$ \\
Dry mouth & very rare $(<1 / 10,000)$ \\
Cardiac disorders: & \\
Tachycardia & rare $(>1 / 10,000,<1 / 1,000)$ \\
Palpitations & \\
Skin and subcutaneous tissue disorders: & rare $(>1 / 10,000,<1 / 1000)$ \\
Skin rash & rare $(>1 / 10,000,<1 / 1000)$ \\
Immune system disorders: & \\
Hypersensitivity reactions & \\
Dyspnoea & \\
General system disorders: & \\
Asthenia & \\
\hline
\end{tabular}


(b) PubMED (http://www.ncbi.nlm.nih.gov/ pubmed): "Clemastine" OR Clemastine Fumarate" OR "klemastyna" OR "15686-51-8" OR "14976-57-9" AND "toxicity" OR "adverse effect" OR "side effect" OR "interaction" OR "risk" OR "safety" OR "carcinogenesis" OR "pregnancy" OR "lactation" OR "child",

(c) Research Gate (www.researchgate.net): "Clemastine" OR "Clemastine Fumarate" OR “klemastyna” OR „15686-51-8” OR „14976-57-9”

(d) RxISK (https://www.rxisk.org/Research/ DrugInformation): "Clemastine" OR Clemastine Fumarate" OR "15686-51-8” OR "14976-57-9"

(e) MedWatch. The FDA Safety Information and Adverse Event Reporting Program. (http://www.fda.gov/Safety/MedWatch/default.ht m): Clemastine" OR Clemastine Fumarate" OR "klemastyna” OR "15686-51-8” OR “14976-57-9".

\section{RESULTS}

During the analyzed period $2,089,717$ packs, each containing 30 Clemastinum Hasco $1 \mathrm{mg}$ tablets, and 1,965,340 packs of Clemastinum Hasco $100 \mathrm{ml}$ syrup were introduced to the market. Spontaneous monitoring revealed one report on the adverse reaction that occurred after administration of three drugs, including one called Clemastinum by an unknown manufacturer, sent by the Office for Registration of Medicinal Products, Medical Devices and Biocidal Products. The report was received on 23rd January 2008 and related to a 4-year-old child that was prescribed 3 medicinal products with a similar activity, namely promethazine, cetirizine and clemastine to treat acute nasal inflammation and pharyngitis (common cold). Adverse reactions observed were drowsiness and dizziness.

The systematic review did not reveal any new adverse reactions from clemastine.

\section{DISCUSSION}

Antihistaminic drugs used to treat common allergies are ubiquitous remedies administered annually in millions of patients worldwide. With such extensive use of a drug, extremely rare adverse events, even those $<1$ per million, are unavoidable. The detection of these rare events is the issue addressed in the studies. Due to practical and financial reasons, active surveillance of millions of patients is not viable, thus pharmacovigilance is based on the analysis of spontaneous reports from healthcare professionals and consumers. According to Summary of Product Characteristics of Tavegil $($ Q [4], the most common $(>1 / 100,<1 / 10)$ adverse effects are: fatigue and drowsiness. Dizziness is uncommon $(>1 / 1,000,<1 / 100)$, while headache, excitability, nausea, dry mouth, hypersensitivity reactions, dyspnoea, asthenia and skin rash belong to rare undesirable effects of clemastine $(>1 / 10,000,<1 / 1,000)$. Listed very rare effects (< 1/10,000) include constipation, tachycardia and palpitations.

It can induce possible paradoxical excitement (e.g., restlessness, insomnia, tremors, euphoria, nervousness, delirium, palpitation, seizures), especially in children, but in general it is well tolerated in patients and clemastine-related adverse reactions are considerably milder compared to other drugs in the same group such as chlorpheniramine or ebastine [5]. Details are shown in Table 1.

As a result of a systematic world literature review on clemastine as an active substance, no new adverse reactions or new information have been found, which might adversely affect the existing benefit-risk ratio of clemastine use in humans.

The three drugs listed above, implicated in the reported adverse reaction have a similar mechanism of action, and a similar adverse event profile, especially in the case of promethazine and clemastine. The most serious of the adverse reactions are drowsiness, impaired coordination, enhancement of the CNS depressant activity of other concomitant drugs and a cholinolytic effect. Woroń et al $[6,7]$ suggest that prescribers should be extremely cautious when administering several antihistamines to be taken concurrently by one patient. When selecting drugs, the risk of drug interactions should be considered so as to prevent an increased risk of serious adverse reactions. The reported symptoms of the adverse reaction should thus be regarded as a cross-drug interaction involving the cumulative depressive effect of said drugs on the CNS. The case described should be treated as a mistake in prescribing medicines of the same effect, as the resulting risk far outweighs the expected benefits. In this case, clemastine does not seem to be the basic cause of the adverse reaction. The analysis of adverse reactions associated with clemastine containing drugs such as Clemastinum Hasco $1 \mathrm{mg}$ tablets and Clemastinum Hasco syrup during their 5-year market presence in Poland proves their safety. Only one adverse reaction report against an estimate of over 3 million therapies may, however, suggest the low sensitivity of the 
existing pharmacovigilance system. This may result from a lack of awareness among medical professionals on the usefulness of any adverse drug-related data, including known and common adverse reactions. The electronic drug safety RxISK database [8] including consumer reports contains 271 reports where clemastine was the suspect drug covering 1,048 reactions, of which 165 do not specify the patient's country. The database contained 3.9 million reports submitted to the FDA's MedWatch from 1st January 2004, to 31st March 2012, of which a third come from outside the United States. These contain 5.1 million drugs suspected of causing 14.5 million adverse effects, so clemastine-related reports constitute $0.005 \%$ of all the reports.

The weakness of this paper is that it is based on passive adverse event reports, its strength being a 5-year observation of the entire Polish population.

\section{CONCLUSION}

No new adverse effect of clemastine was identified. Either formulation of the oral clemastine is a safe medication, rarely causing already known adverse effects. It is, however, likely that the existing spontaneous monitoring system of adverse effects in Poland is not sensitive enough and, therefore, needs improvement.

\section{REFERENCES}

1. Sittig $M \quad(E d)$. Pharmaceutical Manufacturing Encyclopedia 2nd edn, Westwood, NJ: Noyes Publications, 1988.

2. Gilman AG, Rall TW, Nies AS, P. Taylor (Eds). Goodman and Gilman's The Pharmacological Basis of Therapeutics 8th ed, New York, NY: Pergamon Press, 1990.

3. Sweetman SC (Ed). Martindale: The Complete Drug Reference. London, Pharmaceutical Press. Electronic version, 2012. [cited 2012 Oct 30]. Available from: www.medicinescomplete.com/mc/martindale/current/ 2679-

$p . h t m ? q=p a r a c e t a m o l \& t=s e a r c h \& s s=t e x t \& p=5 \# \_h i t$

4. Novartis Consumer Health Tavegil $($ Tablets. Summary of Product Characteristics last updated on the eMC: 16/03/2011 [cited 2012 Oct 30]. Available from: http://www.medicines.org.uk/EMC/medicine/21054/S PC/Tavegil+Tablets/\#UNDESIRABLE_EFFECTS

5. Izumi $N$, Mizuguchi $H$, Umehara $H$, Ogino $S$, Fukui $H$. Evaluation of efficacy and sedative profiles of $H(1)$ antihistamines by large-scale surveillance using the visual analogue scale (VAS). Allergology International 2008; 57(3): 257-263.

6. Woroń J, Kostka-Trabka E. Drug interaction and efficiency and safety of pharmacotherapy in otolaryngology. Otolaryngology. 2003; 2(2): 73-78.

7. Woroń J, Porębski G, Obtułowicz K, Korbut R. Drug safety in pharmacotherapy of allergic diseases. Alergol. Immunol. 2007; 4(1-2): 22-24.

8. RxISK database [cited 2012 Oct 30]. Available from: https://www.rxisk.org/Default.aspx 